\title{
Atrial natriuretic factor responses to submaximal and maximal exercise
}

\author{
K Mandroukas, A Zakas, N Aggelopoulou, K Christoulas, G Abatzides and M Karamouzis \\ Ergophysiology Laboratory, Department of Physical Education and Sports Science, University of Thessaloniki, \\ Greece
}

\begin{abstract}
The aim of this study was to evaluate and compare the plasma concentration of atrial natriuretic factor (ANF), $\mathrm{K}^{+}$, $\mathrm{Na}^{+}$, blood lactate, heart rate, and blood pressure in moderately trained women. Ten healthy women were studied on a cycle ergometer during 20 min of constant submaximal and maximal exercise, as well as during recovery. The ANF concentration was determined by radioimmunoassay. The results show that, except for $\mathrm{Na}^{+}$, all the other variables increased significantly with an increase in the duration and intensity of the exercise $(P<0.05, P<0.001)$. In recovery, the values fell $(P<0.01, P<0.001)$. Submaximal and maximal exercise both cause increases in ANF and this increase is due to the duration and intensity of exercise. However, maximal exercise, rather than submaximal exercise, is the major stimulus for the concentration of plasma ANF. ANF concentration may be a useful test for evaluating the releasing function of ANF in the heart.

(Br J Sports Med 1995; 29 : 248-251)
\end{abstract}

Keywords : submaximal exercise, maximal exercise, plasma atrial natriuretic factor (ANF), potassium, sodium, blood lactate concentration, blood pressure

Atrial natriuretic factor (ANF), or atriopeptin, is a cyclic polypeptide secreted from human atrial tissues in response to increased intra-atrial pressure. ${ }^{1}{ }^{2}$ It induces vasodilatation and blood pressure reduction, decreases renal and hepatic blood flow, and produces a natriuretic and diuretic effect. ${ }^{3-7}$

It has been suggested that the determination of plasma ANF can help to estimate the seriousness of heart disease, act as a sensitive diagnostic indicator, and be a significant index of the physical evolution of the disease. $^{8-11}$ Resting plasma ANF concentrations have been reported to be raised in a spectrum of heart and renal diseases ${ }^{12-16}$ in trained compared with normal individuals, and as well in untrained controls. ${ }^{17-19}$ On the other hand Fellmann ${ }^{20}$ reported that there was no significant difference in resting or maximum exercise ANF values between trained and untrained subjects.

Numerous studies have suggested that higher plasma ANF values are found in disease conditions associated

Address for correspondence: Professor Konstantinos Mandroukas, Department of Physical Education and Sports Science, University of Thessaloniki, Thessaloniki 540-06, Greece. with a pressure or fluid overload of the heart. ${ }^{15}$ Of clinical importance are the findings that both the increase in resting ANF and the much higher plasma ANF found in response to exercise are directly related to the severity of the disease..$^{21}$ It has been shown that strenuous and prolonged physical activity causes a significant increase in plasma ANF. ${ }^{22}$

Knowledge about the effect of short to moderate duration exercise at constant submaximal workload on ANF concentrations is limited. Furthermore, little information exists about maximum exercise intensity on ANF concentrations and their relationship to blood pressure, sodium $\left(\mathrm{Na}^{+}\right)$, potassium $\left(\mathrm{K}^{+}\right)$, and blood lactate concentrations in moderately trained subjects. Thus the aim of this study was to evaluate and compare the ANF secretory patterns during short term constant submaximal and maximal exercise, as well as during recovery, in moderately trained women.

\section{Methods}

Ten healthy female physical education students and volleyball players [mean age $(S D)=20.5(1.64)$ years, height $180.6(5.4) \mathrm{cm}$, weight $68(5.5) \mathrm{kg}$ ] participated in this study. All volunteers were informed about the purpose and possible risks of the study before giving their voluntary written consent to participate. All subjects attended the laboratory early in the morning after an overnight fast from 2100 the previous evening. The subjects were instructed to avoid smoking and strenuous exercise the previous day and to rest in the laboratory for 10 minutes before the blood sampling. The exercise test was performed on an electronic cycle ergometer (Monark) at a pedal rate of $50 \mathrm{rpm}$ indicated by a metronome. All tests were performed in the morning. No warm up was allowed before exercise.

The exercise test started with a submaximal work rate of $100 \mathrm{~W}$ for $20 \mathrm{~min}$ followed by increments of $25 \mathrm{~W}$ every minute until exhaustion. Heart rate was monitored continuously on an electrocardiograph. Blood pressure, with a cuff, and blood samples were obtained at rest, at $10 \mathrm{~min}, 20 \mathrm{~min}$, and immediately after maximum exercise, as well as $10 \mathrm{~min}$ after the end of the maximum exercise (recovery). Blood samples were drawn by a catheter from the brachial vein. The catheter was kept patent with heparinized saline 
throughout the testing period. Blood samples for plasma ANF concentration were collected in prechilled tubes containing EDTA-2Na $(1.5 \mathrm{mg} / \mathrm{ml}$ blood $)$ and aprotinin $(500 \mathrm{KIU} / \mathrm{ml}$ blood), placed on ice, and immediately centrifuged at $1500 \mathrm{~g}$ for $10 \mathrm{~min}$ at $4{ }^{\circ} \mathrm{C}$. Plasma was frozen and stored at $-70^{\circ} \mathrm{C}$ until the assay was performed. The plasma ANF concentration was determined by radioimmunoassay (RIA), using a commercial kit (Amersham). The intra- and interassay coefficients of variation were $6.8 \%$ and $9.8 \%$ respectively and the sensitivity was $7 \mathrm{pg} / \mathrm{ml}$. Serum $\mathrm{K}^{+}$and $\mathrm{Na}^{+}$levels were measured by flame photometry (Eppendorf EDOX 5053). Blood lactate concentration was measured by an enzymatic method (Boehringer, Mannheim). The special characteristics of the method were: (1) specificity: the antibodies bound $100 \%$ of ANF; (2) sensitivity: $7 \mathrm{pg} / \mathrm{ml}$; (3) the coefficient of variance (CV\%) within assay was $6.5 \%$ and $9.8 \%$ between different assays $(n=10)$.

The significance of intraindividual differences was tested using the Wilcoxon test. Pearson productmoment correlation coefficients were also determined. The significance of differences between means was determined by a one way analysis of variance (ANOVA). A value of $P<0.05$ was considered significant.

\section{Results}

The results of the present study showed that heart rate and systolic blood pressure (Figure 1A), blood lactate and ANF concentrations (Figure $1 B$ ), $\mathrm{Na}^{+}$and $\mathrm{K}^{+}$(Figure 1C) increased significantly in response to the duration and intensity of the exercise. After $10 \mathrm{~min}$ and $20 \mathrm{~min}$ of exercise all variables except $\mathrm{Na}^{+}$showed a significant increase in comparison to the rest values $(P<0.01$ to $P<0.001$ ). All variables reached their highest values during maximum exercise. The measurements showed that the maximum values (SEM) over basal level increased as follows: ANF from 49(8.3) to 95.7(18.1) $\mathrm{pg} / \mathrm{ml}(P<0.01)$; systolic blood pressure from $110(2.1)$ to $200(8.2) \mathrm{mm} \mathrm{Hg}(P<0.001) ; \mathrm{K}^{+}$from $4.1(0.1)$ to $5.1(0.2) \mathrm{mmol}^{-1}(P<0.01)$; and plasma lactate concentration from $0.67(0.06)$ to $11.9(0.23) \mathrm{mmol} \mathrm{l}^{-1}$ $(P<0.001)$. The correlations between the different variables after $10 \mathrm{~min}$ and $20 \mathrm{~min}$ of exercise were low. The maximum values of plasma ANF concentrations were not correlated with the maximum values of the other variables. However, significant correlations were found between systolic blood pressure and blood lactate $(r=0.65)$. Ten minutes after maximum exercise (recovery period) the values of all variables except $\mathrm{Na}^{+}$ decreased significantly in comparison to the maximum values $(P<0.005$ for ANF, and $P<0.001$, for heart rate, systolic blood pressure, blood lactate and $\mathrm{K}^{+}$).

\section{Discussion}

The heart rate when measured at an exercise intensity of $100 \mathrm{~W}$ indicated that the subjects were exercising at about $40-50 \%$ of their maximum heart rate. Most of the variables increased significantly in response to exercise.
This increase is not only due to the effect of the exercise intensity, but also to exercise duration. This is shown by there being no increase in exercise intensity until 20 minutes, but a significant increase in heart rate, plasma ANF concentration, blood pressure, and blood lactate. All peak values appear at maximum exercise, which confirms that exercise intensity is a prime factor when exercise is used stimulating plasma ANF production. Mannix et al. ${ }^{3}$ and Goodman et al. ${ }^{17}$ have shown that maximum plasma $\mathrm{ANF}$ and $\mathrm{K}^{+}$concentrations do not appear at the end of maximal exercise, but occur in the first 4 minutes of recovery. The different maximum values of plasma ANF and serum $\mathrm{K}^{+}$between the present study and these previous investigations may be due to methodological differences.

When looking at plasma ANF concentrations in relation to exercise intensity, Tanaka et al. ${ }^{23}$ and Mannix et al. ${ }^{3}$ found increases in plasma ANF concentration at only $30 \%$ of maximum aerobic power in untrained subjects. In contrast, Saito et al..$^{24}$ found no increase in ANF concentration during mild exercise.

The present study shows that exercise duration appears to be an important factor in the increase in ANF concentration. The question is whether the long exercise duration of the same continuous submaximal workload could be a prime factor in the further rise in ANF concentration, as has occurred in maximal exercise. ${ }^{24-27}$

Ten minutes after the end of the exercise (recovery), plasma ANF was significantly reduced, suggesting an immediate reduction in ANF secretion by the heart. This finding is in agreement with previous observations by Brooks et al. ${ }^{28}$ and Follenius and Branderberger. ${ }^{29}$

Heart rate and blood pressure are known to increase significantly with increasing work rates. Some investigators postulate that the exercise tachycardia itself might play a role in ANF stimulation. ${ }^{21}{ }^{30}$ Saito et al. ${ }^{24}$ and Somers et al..$^{31}$ reported that the increase in heart rate during exercise was positively correlated to the changes in ANF. The increase in heart rate itself does not appear to play a major role in the exercise stimulated rise in plasma ANF concentration. Plasma concentrations of ANF during exercise and its potential haemodynamic or cardiovascular effects are known. ${ }^{32}$

The experimental design of the present study was, for the main part, to investigate the changes of plasma ANF concentrations during constant submaximal workload. The results have shown that under these conditions plasma ANF concentration increases with the increase in the duration of the exercise. However, maximal exercise rather than submaximal exercise is the major stimulus for an increase in plasma ANF. This is probably due to different haemodynamic adjustments which occur in the two intensities of exercise. The purpose of most previous studies was to estimate the seriousness of heart and renal disease. In the present study it is shown that plasma ANF concentration increases with exercise intensity and that this response depends on the duration and intensity of the exercise. Exercise in healthy subjects is shown to be a useful test to evaluate the releasing function of ANF in the heart. The determination of plasma ANF provides information on the strain on the cardiovascular system. 
A

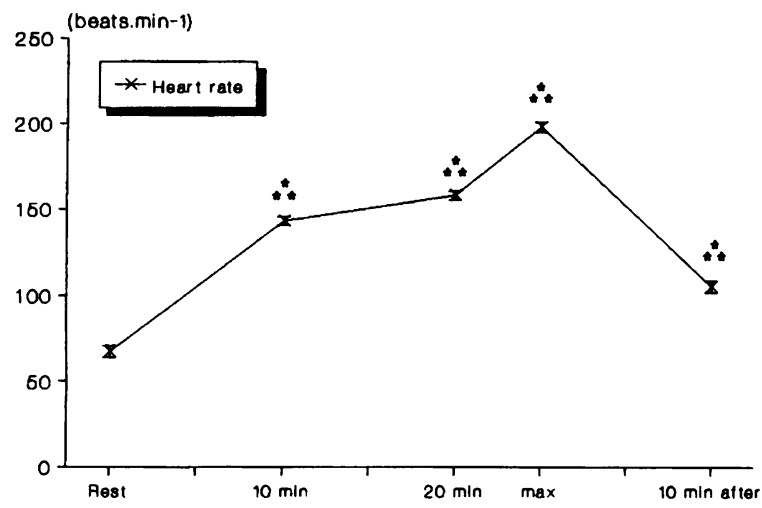

B

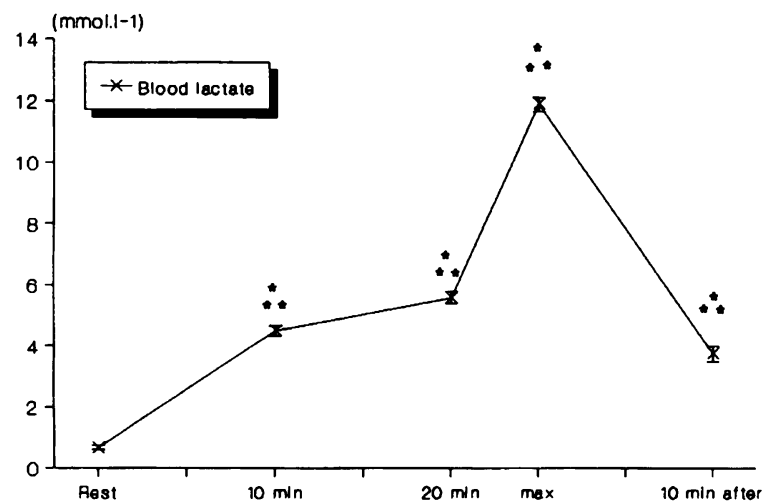

C

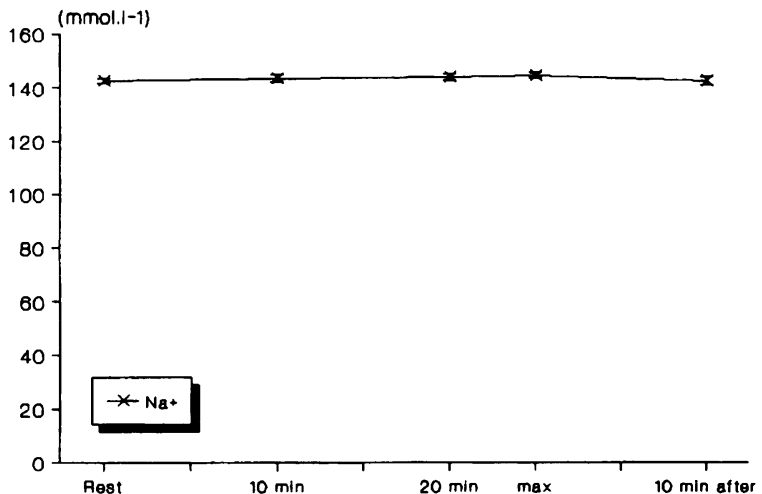

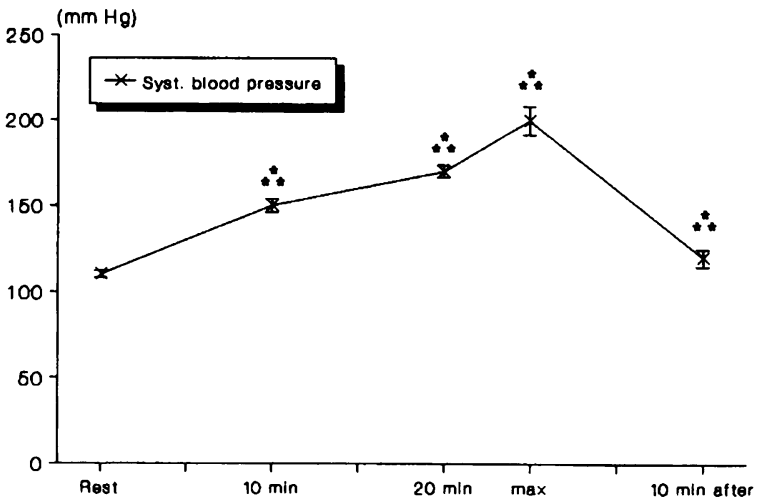
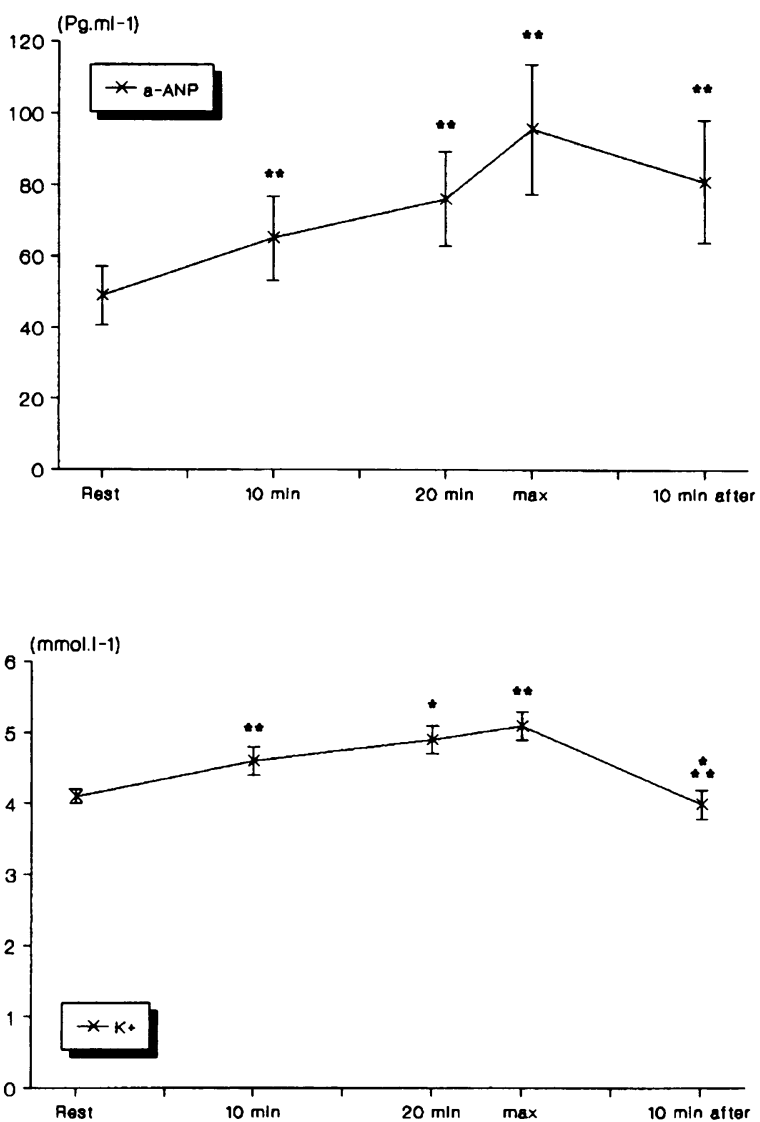

Figure 1. Metabolic and physiological variables at rest, at submaximal and maximal exercise, and at recovery. (A) Heart rate and systolic blood pressure; (B) blood lactate and ANF (a-ANP); (C) $\mathrm{Na}^{+}$and $\mathrm{K}^{+}$. Values are means, error bars $=$SEM. ${ }^{*} P<0.05 ;{ }^{* *} P<0.01 ;{ }^{* * *} P<0.001$

The increase in blood lactate concentration and serum potassium during the 10 and 20 minutes of continuous submaximal constant workload could be due to local fatigue of the quadriceps muscle. On the other hand, the unchanged value of sodium during the submaximal and maximal exercise is difficult to explain.

In conclusion, our study clearly shows that plasma ANF concentration increases in response to the intensity of exercise, indicating that an exercise test can evaluate not only cardiorespiratory function but also the endocrine function of the heart. Further study is needed to determine whether long duration exercise until exhaus- tion can lead to maximal ANF concentrations. Also, the ANF response during a long period of constant submaximal workload in these individuals remains to be investigated.

\section{References}

1 DeBold AJ, Borenstein HB, Veress AT, Sonenberg H. A rapid and potent natriuretic response to intravenous injection of atrial myocardial extract in rats. Life Sci $1981 ; 28$ : 89-94.

2 Muller FB, Erne P, Raine AE, et al. Atrial antipressor natriuretic peptide: release mechanisms and vascular action in man. $J$ Hypertens 1986; (suppl 2): S109-14. 
3 Mannix E, Palange P, Aronoff G, Manfredi F, Farber M. Atrial natriuretic peptide and the renin aldosterone axis during exercise in man. Med Sci Sports 1990; 22 : 785-9.

4 Naruse M, Naruse K, Obana K, et al. Immunoreactive alpha-human atrial natriuretic polypeptide in human plasma. Peptides 1986; 7 : 141-5.

5 Biollaz J, Nussberger J, Waeber B, Brunner HR. Clinical pharmacology of atrial natriuretic (3-28) eicosahexapeptide. J Hypertens 1986; 4 : (suppl) S101-8.

6 Laragh JH. ANP A New Element for Control of Blood Pressure and Sodium Volume Homeostasis. In: L Hanson, ed. Hypertension. London: Gower, 1986: 27-39.

7 Needleman P, Greenwasaed J. Atriopeptin, a cardiac hormone intimately involved in fluid electrolyte and blood pressure homeostasis. $N$ Engl J Med 1986; 314: 828-34.

8 Lundin L, Oberg K, Landelius J, Hansson HE, Wilander E Theodorsson E. Plasma atrial natriuretic peptide in carcinoid heart disease. Am J Cardiol 1989; 63: 969-72.

9 Fridrich L, Szekeres T, Hartter E, Schweighofer F, Gassner A, Laczkovic A. Correlation between heart disorders and concentration of directly measured atrial natriuretic peptide in plasma. Clin Chem 1989; 35 : 435-9.

10 Lang RE, Dietz R, Meriel A, Unger T, Ruskoaho H, Ganten D. Plasma atrial natriuretic peptide values in cardiac disease. $J$ Hypertens 1986; (suppl 2): S119-23.

11 Nicklas JM, Di Carlo LA, Koller PT, et al. Plasma levels of immunoreactive atrial natriuretic factor increase during supraventricular tachycardia. Am Heart J 1986; 112 : 923-8.

12 Sugawara A, Nakao K, Morii N. a-human atrial natriuretic polypeptide is released from the heart and circulates in the body. Biochem Biophys Res Commun 1985; 129: 439-46.

13 Sugawara A, Nakao K, Sakamoto M, et al. Plasma concentration of atrial natriuretic polypeptide in essential hypertension. Lancet 1985 ; ii: $1426-7$.

14 Keller N, Sykulski R, Thamsborg G, Storm T, Larsen J. Changes in atrial natriuretic factor during preload reduction with nitroglycerin in patients with congestive heart failure. Clin Physiol 1988; 8: 57-64.

15 Morris M, Cain M, Russell A, Elliot J, Chalmers J. Direct and radioimmunoassay of human plasma atrial natriuretic peptide in various normal pathophysiological states: increase in renal and cardiac failure during exercise. Clin Exper Theory Practice 1987, A9: 703-18.

16 Freund BJ, Claybaugh JR, Dice MS, Hashiro GM. Hormonal and vascular fluid responses to maximal exercise in trained and untrained males. J Apl Physiol 1987; 63: 669-75.

17 Goodman JM, Logan AG, McLaughlin PR, et al. Atrial natriuretic peptide (ANP) during exercise in normal, heart failure and hypertensive subjects. (Abstract) Med Sci Sports Exerc 1989; 21 : suppl S11.

18 DeCholnoky A, Neuberg GW, Pajaro RE. Endurance training augments the rise in plasma atrial natriuretic factor during exercise in man. (Abstract) Med Sci Sports Exerc 1989; 21 : (suppl) S11.

19 Roberts WC, Ferans VJ. Pathologic anatomy of the cardiomyopathies. Hum Pathol 1975 ; 6 : 287-342.

20 Fellmann N. Hormonal and plasma volume alterations following endurance exercise. Sports Med 1992; 13: 37-49.

21 Fyhrquist F, Tikkanen I, Totterman KJ, Hynynen M, Tikkanen T Andersson S. Plasma atrial natriuretic peptide in health and disease. Eur Heart J 1987; 8 (suppl B): 117-22.

22 Karamouzis M, Mandroukas K, Deligiannis A, et al. Changes in atrial natriuretic peptide (a-ANP) in long distance swimmers. Clin Chem Enzyme Commun 1994; 6 : 191-5.

23 Tanaka H, Shindo M, Gutkowska J, et al. Effect of acute exercise on plasma immunoreactive-atrial natriuretic factor. Life Sci 1986; 39 : 1685-93.

24 Saito Y, Nakao K, Sugawara A. Atrial natriuretic polypeptide during exercise in healthy man. Acta Endocrinol (Copenh) 1987 116: $59-65$.

25 Adnot $\mathrm{S}$, Chabrier $\mathrm{PE}$, Andrivet $\mathrm{P}$, et al. Atrial natriuretic peptide concentrations and pulmonary hemodynamics in patients with pulmonary artery hypertension. Am Rev Respir Dis 1987; 136: 951-6.

26 Richards AM, Tonolo G, Cleland JG, et al. Plasma atrial natriuretic peptide concentrations during exercise in sodium replete and deplete normal man. Clin Sci 1987; 72: 159-64.

27 Odaglia G, Barreca T, Reggiani G, et al. Atrial natriuretic peptide (ANP) secretion after exhaustive and submaximal exercise in athletes. Med Sci Res 1988; 16: 999-1000.

28 Brooks S, Nevill ME, Meleagros L, et al. The hormonal responses to repetitive brief maximal exercise in humans. Eur J Appl Physiol 1989; 60: $144-8$

29 Follenius $M$, Branderberger $G$. Increase in atrial natriuretic peptide in response to physical exercise. Eur J Appl Physiol 1988; 57: 159-62.

30 Espiner EA, Nicholls MG, Vandlet TG, et al. Studies on the secretion, metabolism and action of atrial natriuretic peptide in man. J Hypertens 1986; 4 : Suppl S85-91.

31 Somers VK, Anderson JV, Conway A, Sleight P, Bloom SR. Atria natriuretic peptide is released by dynamic exercise in man. Horm Metab Res 1986; 18: 871-2.

32 Freund B, Wade CE, Claybaugh J. Effects of exercise on atria natriuretic factor release: mechanisms and implications for fluid homeostasis. Sports Med 1988; 6: 364-76. 